\title{
Horizontal Bearing Capacity of A New Bucket Foundation with Partial Inclined Wall
}

\author{
Liu Jin-long ${ }^{*}, 1$ and Chen Lu-wang ${ }^{2}$ \\ ${ }^{I}$ Department of Civil Engineering, Hefei University, Hefei230022, China \\ ${ }^{2}$ School of Resource and Environmental Engineering, Hefei University of Technology, Hefei 230009, \\ China
}

\begin{abstract}
The traditional bucket foundation use vertical wall, which like a cup is buried upside down in seabed. A new bucket foundation with partial inclined wall has been proposed in this article. Based on limit equilibrium analysis of threedimensional stress state of foundation, the calculation method of the horizontal bearing capacity of the new bucket foundation has been deduced, which has been verified by model tests. It is found that the horizontal bearing capacity of the new bucket foundation increased effectively when dip angle of wall is increased. The horizontal bearing capacity of the new bucket foundation increased with the proportional coefficient of horizontal subgrade reaction, top diameter or height of bucket foundation increased respectively, while it decreased when the depth of seabed was increased. The parameters of the new bucket foundation should be determined by geological conditions of seabed, physical and mechanical parameters of marine soil, design value of horizontal bearing capacity and construction method. The research results would be conducive to optimize design of traditional bucket foundation.
\end{abstract}

Keywords: Bucket foundation, horizontal bearing capacity, partial inclined wall, sensitivity analysis of parameters.

\section{INTRODUCTION}

It is very difficult to build marine Engineering in ocean, because of the very bad environmental and geological conditions. The big thickness and large scope seabed covered with soft soil, silt and liquefiable sandy soil increase the difficulty and investment risk of marine Engineering. Bucket foundation, a new foundation top closed and bottom opened, which like a cup upside down is buried in seabed, is adapt to the character of seabed and could be used as foundation, of offshore wind power project (as showed in Fig. 1),offshore oil and gas resources project, and mooring project for floating structures at sea [1-6].

The traditional bucket foundation is with vertical wall are, just like cylinders. The foundations of Europipe 16/11-E of Norway are composed of 4 bucket foundations with diameter of $12.0 \mathrm{~m}$, height of $9.5 \mathrm{~m}$ and weight of 5240 tons [7]. The suction anchor of QHD32-6-4 at southwest Gulf of Bohaiis used with bucket foundations with diameter of $3.2 \mathrm{~m}$, height of $6.0 \mathrm{~m}$ and weight of 35 tons. The suction anchor of Wenchang13-1oilfield, Wenchang13-2 oilfield at western Nanhai of China are used with bucket foundations with diameter of $5.0 \mathrm{~m}$, height of $11.5 \mathrm{~m}$ and weight of 50 tons [8].

*Address correspondence to this author at the Department of Civil Engineering, Hefei University, Hefei230022, China;

Tel: 0551-62158417; Fax: 0551-2158466;

E-mail: liujlo@hfuu.edu.cn

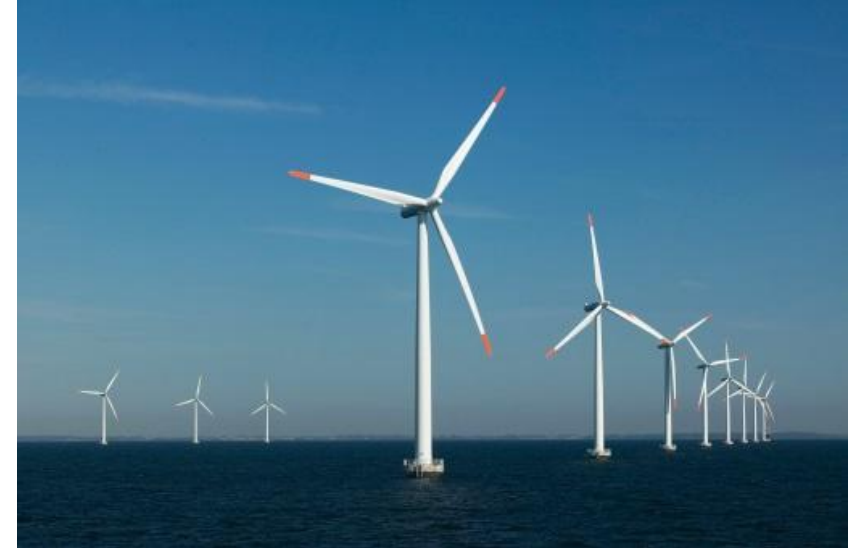

Fig. (1). Offshore wind power project.

In fact, in order to diffuse the stress on large area of seabed, bucket foundation could be inclined of wall like taper [9, 10]. A type of whole tapered bucket foundation has been proposed by the authors of this article, as showed in Fig. (2a), and the horizontal bearing capacity of which has been deduced with limit equilibrium method. But attention the following problems are worth consideration:

(1) The bucket foundation is closed and could be vacuumed by pumping of the air, which can be installed into seabed by the pressure of sea water. But when the wall of bucket foundation is inclined outward, more and more marine soil squeezed into the bucket foundation therefor, the friction pressure between bucket foundation wall and 


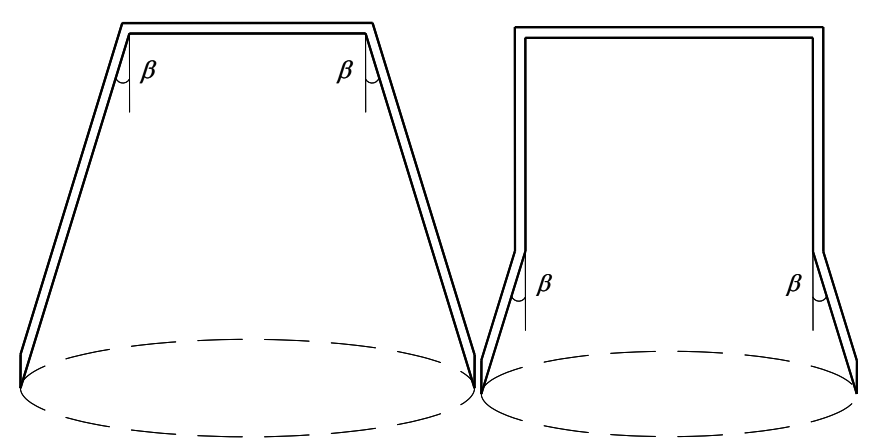

(a) whole wall inclined

(b) partial wall inclined

Fig. (2). Analytic model of the tapered bucket foundation.

marine soil become more and more bigger. That is, it is more and more difficult to penetrate bucket foundation into seabed with the increasing depth of penetration. In a certain degree, the construction condition of sea is very complex. So the bucket foundation with whole inclined wall could hardly be applied and developed in marine engineering without convenient and efficient construction characteristics.

(2) It is found that the horizontal bearing capacity of bucket foundation with whole inclined wall increased greatly when dip angle of wall increased. But the bearing characteristics of bucket foundation should be a combination of horizontal bearing capacity, vertical bearing capacity, torque bearing capacity and moment bearing capacity. That is, it is ideal and reasonable that all of those bearing capacities increased synchronously or equally. Therefore, it is not an optimal design of bucket foundation with whole inclined wall for other bearing capacity maybe not increased synchronously with horizontal bearing capacity.

In geotechnical engineering, expanding bottom pile is a cast-in-place pile that the diameter of bottom is bigger than that of upper, which greatly increased the bearing capacity of single pile. Actually, the bucket foundation could also be optimized design with partial wall inclined like expanding bottom pile, a new bucket foundation proposed by the authors of this article, as showed in Fig. (2b). Compared with the bucket foundation with whole inclined wall, bucket foundation with partial inclined wall could be constructed and penetrated into seabed more easily and effectively. And the bearing capacity of bucket foundation with partial inclined wall would be bigger than that of bucket foundation with vertical wall.

There is no effective method to calculate the bearing capacity and stability of the new bucket foundation with partial inclined wall, especially lacking effective test data. Therefore, based on limit equilibrium method, the horizontal bearing capacity of the new bucket foundation with partial inclined wall is studied systematically in this article, the influence of dip angle of wall, height of foundation, diameter of foundation, parameters of soil and depth of seabed on the horizontal bearing capacity have been analyzed, which aim to promoting the design and application of the new bucket foundation in marine engineering.

\section{CALCULATION METHOD OF HORIZONTAL BEARING CAPACITY}

\subsection{Analytic model of the new bucket foundation}

The stress conditions of bucket foundation with partial inclined wall at limit equilibrium state is showed in Fig. (3), where $H$ is the height of bucket foundation (m), $D$ is the top diameter of bucket foundation(m), $\beta$ is the dip angle of wall $\left({ }^{\circ}\right), P_{u}$ is horizontal bearing capacity of bucket foundation $(\mathrm{kN}), L_{p}$ is the height of $P_{u}(\mathrm{~m})$.

$\sigma_{x}$ is the horizontal resistance stress of soil acted on outer wall of bucket foundation $(\mathrm{kPa}), \sigma_{z}$ is the vertical resistance stress of soil acted on bottom of bucket foundation $(\mathrm{kPa}), T_{1}$ is the friction force between soil and outer wall at front side of bucket foundation $(\mathrm{kN}), T_{2}$ is the friction force between soil and outer wall at posterior side of bucket foundation $(\mathrm{kN}), T_{b}$ is the friction force between soil and bottom of bucket foundation $(\mathrm{kN})$. The bucket foundation would be failure or rotated around point $A$ by horizontal bearing capacity $P_{u}$.

\subsection{Assumption of the Analytic Model}

(1) The bucket foundation with whole inclined wall (as showed in Fig. (2a)) has been analyzed by the authors of this article already, which revealed that the position of point $A$ is irrelevant with the value of dip angle of wall $\beta$. That is, the height of point $A$ is about $2 H / 3$, which amplitude of variation little than $5 \%$ with different value of dip angle of wall $\beta$.

Therefore, the height of point $A$ is assumed as $2 H / 3$, as showed in Fig. (3a), which simplified the mechanical analysis process of the model. The bucket wall upper than point $A$ (height of $2 H / 3$ ) remain vertical, while the bucket wall below than point $A$ (height of $H / 3$ ) would be tilted outward with angle $\beta$, which is the new bucket foundation with partial inclined wall mentioned above.

(2) There inner of bucket foundation is filled with marine soil, there is no void between soil and inner of bucket foundation, and there is no relative displacement between soil and inner of bucket foundation. That is, the bucket foundation and the inner soil is considered as a uniform rigid body.

(3) The horizontal resistance stress of soil acted on outer wall of bucket foundation obeys the Winkler assumption, which presented as parabola distribution along the height of bucket foundation, as showed in Fig (3a). In $x o z$ coordinate axis, the horizontal resistance stress of soil could be expressed as following:

$\sigma_{x 0}=k_{x}\left(z-\frac{2 H}{3}\right) \omega$

where $k_{x}$ is the coefficient of horizontal subgrade reaction, $k_{x}=m z, m$ is the proportionality constant determined by 


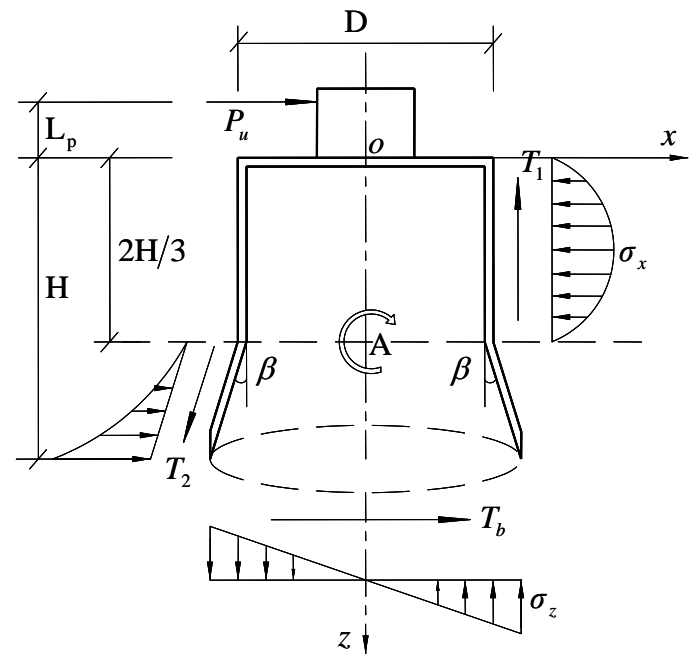

(a) Longitudinal section

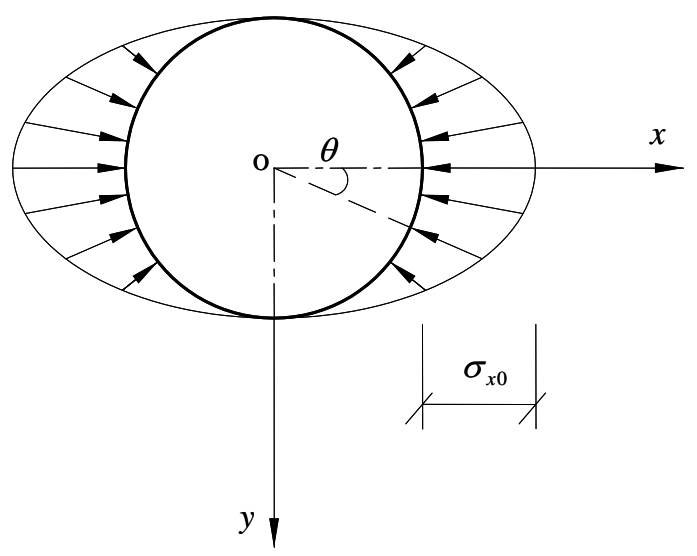

(b) Cross section

Fig. (3). Analytic model of the bucket foundation with partial inclined wall.

the test. $\omega$ is the rotation angle of bucket foundation by the action of horizontal load.

(4) In xoy coordinate axis, the horizontal resistance stress of soil agreed with the trigonometric function distribution, as showed in Fig (3b), which could be expressed as following:

$\sigma_{r}=\sigma_{x 0} \cos \theta$

where $\sigma_{r}$ is the radial horizontal resistance stress of soil, $\sigma_{x 0}$ is the maximal horizontal resistance stress of soil. The component of $\sigma_{r}$ along the $x$ axis could be calculated as following:

$\sigma_{x}=\sigma_{r} \cos \theta=\sigma_{x 0} \cos ^{2} \theta$

(5) The friction stress $\tau_{z}$ on the outerbucket foundation is proportional with the value of radial horizontal resistance stress, could be calculated as following:

$\tau_{z}=f \sigma_{r}$ where $f$ is the coefficient of friction between soil and bucket foundation, determined by the test.

(6) The vertical resistance stress of soil acted on bottom of bucket foundation $\sigma_{z}$ is also obeys the Winkler assumption, as showed in Fig (3a), could be calculated as following:

$\sigma_{z}=-k_{z} x \omega$

where $k_{z}$ is the coefficient of vertical subgrade reaction, $k_{z} \approx 2 k_{x}[11]$.

\subsection{Stress Analysis of Bucket Foundation}

(1) The force $N_{1}$ produced by the horizontal resistance stress of soil on outer wall at front side of bucket foundation could be calculated as following (as showed in Fig. (4a)):

$N_{1}=\iint_{S(\text { front) }} \sigma_{x} \mathrm{~d} s=2 \int_{0}^{\frac{2 H}{3}} \int_{0}^{\frac{\pi}{2}} \sigma_{x} \frac{D}{2} \mathrm{~d} \theta \mathrm{d} z=-\frac{m \omega \pi D}{81} H^{3}$

(2) The force $\mathrm{N}_{2}$ produced by the horizontal resistance stress of soil on outer wall at posterior side of bucket foundation could be calculated as following (as showed in Fig. (4b)):

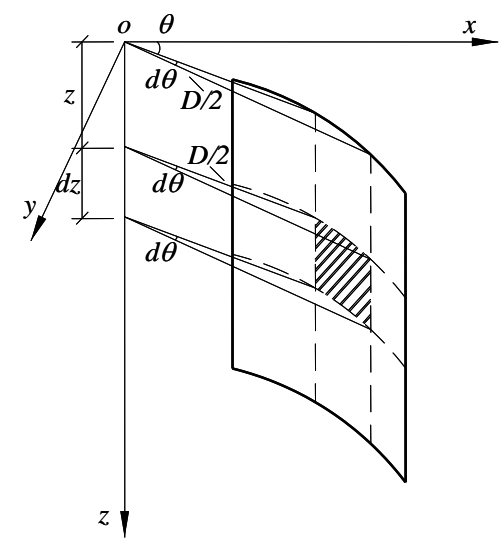

(a) Vertical wall of bucket foundation

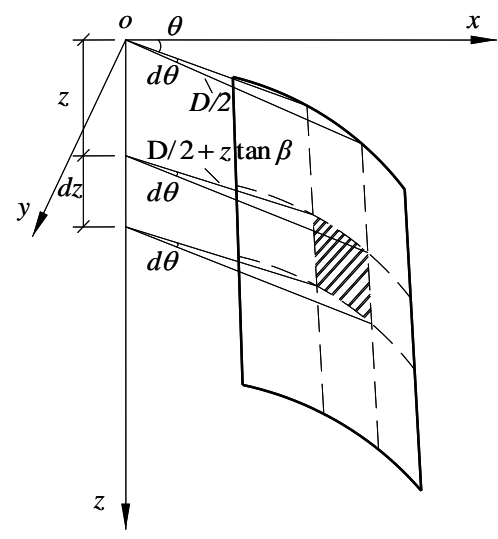

(b) Inclined wall of bucket foundation

Fig. (4). Mathematical integral on the wall of bucket foundation. 
$N_{2}=\iint_{S \text { (posterior) }} \sigma_{x} \mathrm{~d} s=2 \int_{\frac{2 H}{3}}^{H} \int_{0}^{\frac{\pi}{2}} \sigma_{x}\left[\frac{D}{2}+\left(z-\frac{2 H}{3}\right) \tan \beta\right] \mathrm{d} \theta \mathrm{d} z$

(3) The

friction force

$T_{1}$

be $=\frac{m \omega \pi}{2}\left(\frac{11}{972} H^{4} \tan \beta+\frac{2}{81} H^{3} D\right)$ tween soil and outer wall at front side of bucket foundation could be calculated as following:

$T_{1}=\iint_{S \text { (front) }} \tau_{z} \mathrm{~d} s=2 \int_{0}^{\frac{2 H}{3}} \int_{0}^{\frac{\pi}{2}} \tau_{z} \frac{D}{2} \mathrm{~d} \theta \mathrm{d} z=-\frac{4}{81} m \omega f D H^{3}$

(4) The friction force $T_{2}$ between soil and outer wall at posterior side of bucket foundationcould be calculated as following:

$$
\begin{aligned}
& T_{2}=\iint_{S \text { (posterior) }} \tau_{z} \mathrm{~d} s=2 \int_{\frac{2 H}{3}}^{H} \int_{0}^{\frac{\pi}{2}} \tau_{z}\left[\frac{D}{2}+\left(z-\frac{2 H}{3}\right) \tan \beta\right] \mathrm{d} \theta \mathrm{d} z \mathrm{~h} \\
& =m \omega f\left(\frac{4}{81} H^{3} D+\frac{11}{486} H^{4} \tan \beta\right)
\end{aligned}
$$

(5) The bending moment $M_{1}$ generated by $N_{1}$ around point $A$ by could be calculated as following:

$$
M_{1}=\iint_{S(\text { front })} \sigma_{x}\left(\frac{2 \mathrm{H}}{3}-\mathrm{z}\right) \mathrm{d} s
$$

(6) The bending moment $M_{2}$ generated by $N_{2}$ around point $A$ by could be calculated as following:

$$
M_{2}=\iint_{S(\text { posterior })} \sigma_{x}\left(z-\frac{2 \mathrm{H}}{3}\right) \mathrm{d} s
$$

(7) The bending moment $M_{b}$ generated by $\sigma_{z}$ around point $A$ by could be calculated as following:

$$
M_{b}=\iint_{S(\text { bottom })} \sigma_{z} x \mathrm{~d} s=\frac{k_{z} \omega \pi}{4}\left(\frac{D}{2}+\frac{H}{3} \tan \beta\right)^{4}
$$

Combining with the force balance at $x$ axis direction, the force balance at $z$ axis direction and the bending moment balance around point $A$, the expression of horizontal bearing capacity $P_{u}$ could be deduced as following:
$P_{u}=\frac{1}{H+L_{p}}\left\{\frac{k_{z} \omega \pi}{4}\left(\frac{D}{2}+\frac{H}{3} \tan \beta\right)^{4}+\right.$

$\frac{m \omega f D H^{3}}{2}\left(\frac{4}{81} D+\frac{11 H}{486} \tan \beta\right) \cos \beta+$

$\left.\frac{2 m \omega f}{81} D^{2} H^{3}+\frac{7 m \omega \pi}{4860} H^{5} \tan \beta+\frac{m \omega \pi}{144} D H^{4}\right\}$

That is, the horizontal bearing capacity ofthe new bucket foundation with partial inclined wall proposed in this article could be calculated with Eq. (13). It should be mentioned that simplified and approximatemathematical treatment has been used during the mathematical derivation of Eq.(13).

The traditional bucket foundation with vertical wall could be treated as a special case of bucket foundation with partial inclined wall with $\beta=0^{\circ}$, so the horizontal bearing capacity of which could be deduced from Eq.(13) when $\beta=0^{\circ}$ :

$$
P_{u}=\frac{\omega}{H+L_{p}}\left\{\frac{k_{z} \pi D^{4}}{64}+\frac{4 m f}{81} H^{3} D^{2}+\frac{m \pi}{144} H^{4} D\right\}
$$

It can be found that Eq.(14) is the same formula proposed in reference [11]. Therefore, the horizontal bearing capacity of bucket foundation proposed in reference [11] could be treated as a special case proposed in this article when $\beta=0^{\circ}$.

\section{COMPARISON BETWEEN THEORETICAL RESULTS AND MODEL TEST RESULTS}

There is few model test about bucket foundation, and bucket foundation with partial inclined wallis rarely mentioned in literature. A model test about bucket foundation with vertical wall had been provided in ref. [4], with the parameters of $D=0.5 \mathrm{~m}, L_{p}=0.1 \mathrm{~m}$,

$\omega=0.02 \mathrm{rad}$ and $f=0.3278$. The value of $m--$ proportionality constant coefficient of horizontal subgrade reaction has not been given in ref. [12]. According to "Technical Code for Building Pile Foundations ", the value of soft flowing mucky clay is $m=6 \sim 14 \mathrm{MN} / \mathrm{m}^{4}$. So the value of $m$ in model test of ref. [12] could be estimated as $\mathrm{m}=8000 \mathrm{kN} / \mathrm{m}^{4}$. The comparison between theoretical results and model test value of horizontal bearing capacity of foundation is showed in Table 1.

Table 1. Comparison between theoretical results and model test value of horizontal bearing capacity of foundation ( $\mathrm{kN}$ ).

\begin{tabular}{|c|c|c|c|c|}
\hline $\boldsymbol{H} / \mathbf{m}$ & $\boldsymbol{P}_{\mathbf{u}}$ from test & $\boldsymbol{P}_{\mathbf{u}}$ from ref.[12] & $\boldsymbol{P}_{\mathbf{u}}$ from ref.[13] & $\boldsymbol{P}_{\mathbf{u}}$ from Eq.(13) \\
\hline \hline 0.3 & 1.0 & 0.932 & 3.59 & 0.82 \\
\hline 0.5 & 1.2 & 1.275 & 3.88 & 1.13 \\
\hline 0.8 & 1.65 & 1.576 & 5.0 & 2.04 \\
\hline
\end{tabular}


It can be found that there is acceptable error between model test result and the value of ref. [12] or Eq. (13) proposed in this article. The error between model test result and the value of ref. [13] is very large. Many factors have been considered in the formula proposed in ref. [12], which caused the expression is an implicit equation, and the value of horizontal bearing capacity of foundation could be got only through complex iterative calculation. That is, it is not easy or convenient to use the formula proposed in ref. [12] in engineering. Therefore, the calculation method of horizontal bearing capacity ofbucket foundation with partial inclined wall proposed in this article maybe is an accepted method, with the characters of accurate, convenient, feasible and concise.

It need to point out that the method has been validated only by small scale indoor model test, which is an attempt or experimentto calculate the horizontal bearing capacity of bucket foundation with partial inclined wall. Large scale model test, such as 1:1, should be carried out to study the new bucket foundation further.

\section{SENSITIVITY ANALYSIS OF PARAMETERS}

There are many parameters in the Eq. (13), a calculation method ofhorizontal bearing capacity ofbucket foundation with partial inclined wall proposed in this article. So it is necessary to evaluate the influence of each parameter on horizontal bearing capacity of bucket foundation, that is, sensitivity analysis of parameters.

Now a suction anchor (May of 2003) of mooring system for floating platform in Fan-Yu oilfield 4-2 and Fan-Yu oilfield 5-1 is to be studied. The parameters are list as following: $D=5.0 \mathrm{~m}, H=11.5 \mathrm{~m}, L_{p}=105.0 \mathrm{~m}$, $\omega=0.02 \mathrm{rad}, f=0.3278, \mathrm{~m}=8000 \mathrm{kN} / \mathrm{m}^{4}$. During the sensitivity analysis of parameters, the value of appointed parameter changed only and other parameters remain the original value.

\subsection{Influence of Dip Angle of Wall $\beta$ on $P_{u}$}

The influence of dip angle of wall $\beta$ on horizontal bearing capacity $P_{u}$ is showed in Fig. (5). It can be found that the horizontal bearing capacity of bucket foundation with whole inclined wall increased quickly and obviously with dip angle of wall increased. The horizontal bearing capacity at $\beta=4^{\circ}, \beta=8^{\circ}, \beta=12^{\circ}$ is more bigger than that of $\beta=0^{\circ}$ with percentage increase of $63.1 \%, 176.0 \%$, $371.0 \%$ respectively. As mentioned above, although the horizontal bearing capacity increased rapidly with whole inclined wall, it is difficult to penetrate or construct bucket foundation with whole inclined wall in practical engineering.

If only the bucket wall below than point $A$ (height of $H / 3$ ) tilted outward with angle $\beta$, the horizontal bearing capacity at $\beta=4^{\circ}, \beta=8^{\circ}, \beta=12^{\circ}$ is more bigger than that of $\beta=0^{\circ} \quad$ with percentage increase of $13.6 \%, 31.1 \%$, $53.6 \%$ respectively. That is, the horizontal bearing capacity could also be increased effectively with partial inclined wall. Furthermore, it is easyand feasibly to penetrate or construct bucket foundation with partial inclined wall in practical engineering. It is important to got this feature or essence of bucket foundation with partial inclined wall, which would improve and optimize the design of bucket foundation.

\subsection{Influence of Proportional Coefficient of Horizontal Subgrade Reactionm on $P_{u}$}

During the deduction of Eq. (13) mentioned above, the calculation of earth pressure act on outer side or bottom of bucket foundation is lies on a parameter----proportional coefficient of horizontal subgrade reaction $m$. In a certain degree, the parameter $m$ represent engineering geological conditions of seabed, physical and mechanical character of marine soil. Therefore, it is important to get the accurate value of $m$.

The influence of proportional coefficient of horizontal subgrade reaction $m$ on horizontal bearing capacity of bucket foundation with partial inclined wall $P_{u}$ with $\beta=8^{\circ}$ is showed in Fig. (6). It can be found $P_{u}$ linearly increased with value of $m$ increased.

But there are many factors affecting the value of $m$, so it is difficult to measure the value of $m$ accurately. According to "Technical Code for Building Pile Foundations, "the value of $m$ could be influenced by type of foundation soil, type of piles, property of loading, and so on. The value of soft plastic clayey soil with precast concrete pile or steel pile is $m=4.5 \sim 6.0 \mathrm{MN} / \mathrm{m}^{4}$, while that of bored pile is $m=6.0 \sim$ $14.0 \mathrm{MN} / \mathrm{m}^{4}$. It can be seen large range value of $m$ suggested by code, so the value of $P_{u}$ is not easy to be determined accurately. It is urgently necessary to establish a test method to measure the value of $m$ of seabed, and provide corresponding detail sheets to search the value of $m$ for users conveniently.

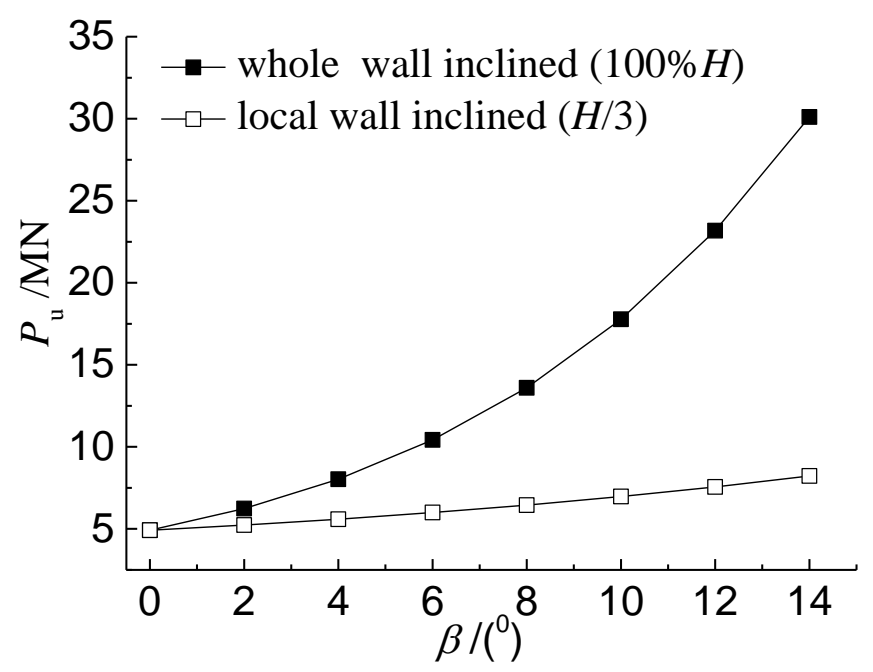

Fig. (5). Influence of dip angleof wall $\beta$ on horizontal bearing capacity of foundation $P_{\mathrm{u}}$. 


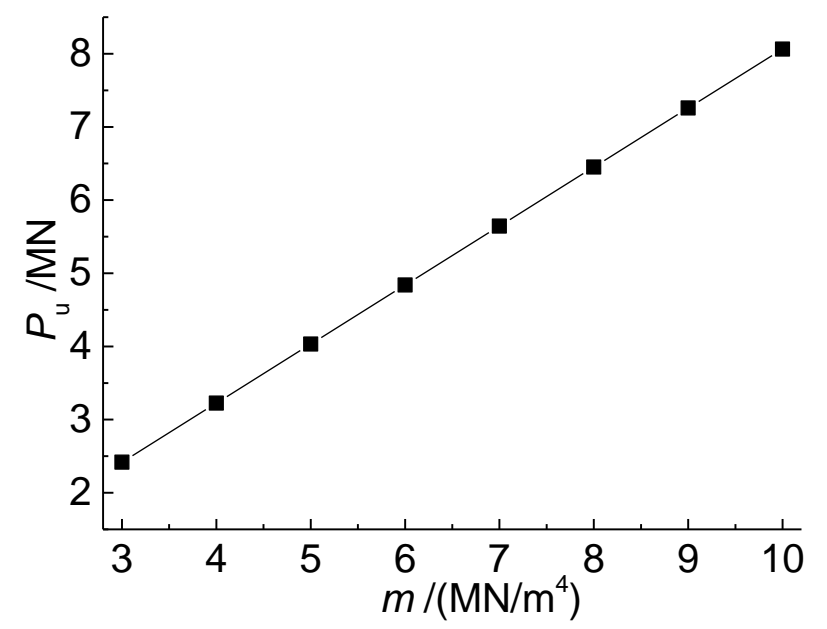

Fig. (6). Influence of proportional coefficient of soil resistance $m$ on horizontal bearing capacity of foundation $P_{\mathrm{u}}$.

\subsection{Influence of Size of Bucket Foundationon $P_{u}$}

The relationship between top diameter of bucket foundation $D$ and $P_{u}$ at $\beta=6^{\circ}$ is showed in Fig. (7), and the relationship between height of bucket foundation $H$ and $P_{u}$ at $\beta=10^{\circ}$ is showed in Fig. (8). It can be found that the horizontal bearing capacity $P_{u}$ increased rapidly with top diameter of bucket foundation or height of bucket foundation increased.

The ratio between height and top diameter of bucket foundation $H / D$ is an key parameters during bucket foundation design. The influence of $H / D$ on horizontal bearing capacity $P_{u}$ at $\beta=8^{\circ}$ and $D=5.0 \mathrm{~m}$ is showed in Fig. (9). It can also be found that the horizontal bearing capacity $P_{u}$ increased rapidly and with the value of $H / D$ increased. But it is difficult to construct or penetrate the bucket foundation when $H / D$ increased.

Therefore, the reasonable value of $D, H$ and $\beta$ during bucket foundation design should be comprehensively decided by geological conditions of seabed, physical and mechanical parameters of marine soil, design value of horizontal bearing capacity and construction method, etc.

\subsection{Influence of Depth of Seabed on $P_{u}$}

The bucket foundation could be used as foundation of offshore wind power project,offshore oil and gas resources project and mooring project for floating structures at sea. While those engineering are important influenced by the depth of seabed. The height of offshore platform increased when the depth of seabed increased. That is, the height of horizontal bearing capacity $L_{\mathrm{p}}$ increased when the depth of seabed increased. In a certain degree, the value of $L_{\mathrm{p}}$ could represent the depth of seabed.

The influence of depth of seabed $L_{p}$ on $P_{u}$ at $\beta=6^{\circ}$ is showed in Fig. (10). The horizontal bearing capacity of

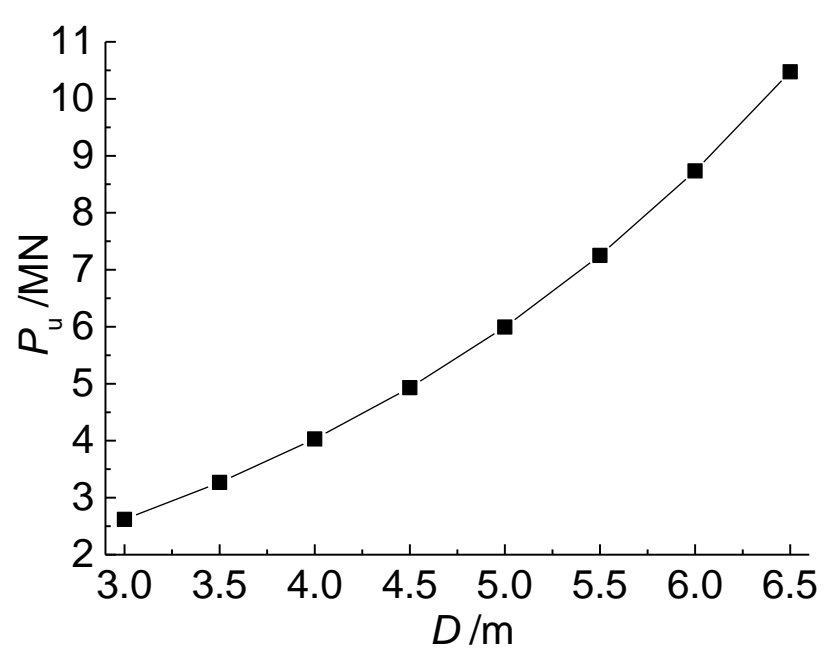

Fig. (7). Influence of top diameter of bucket $D$ on horizontal bearing capacity of foundation $P_{\mathrm{u}}$.

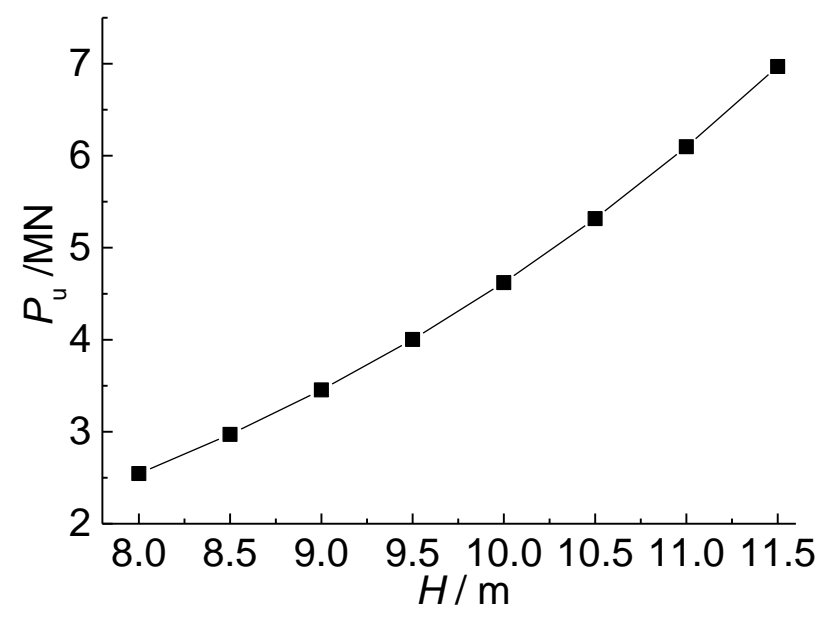

Fig. (8). Influence of height of bucket foundation $H$ on horizontal bearing capacity of foundation $P_{\mathrm{u}}$.

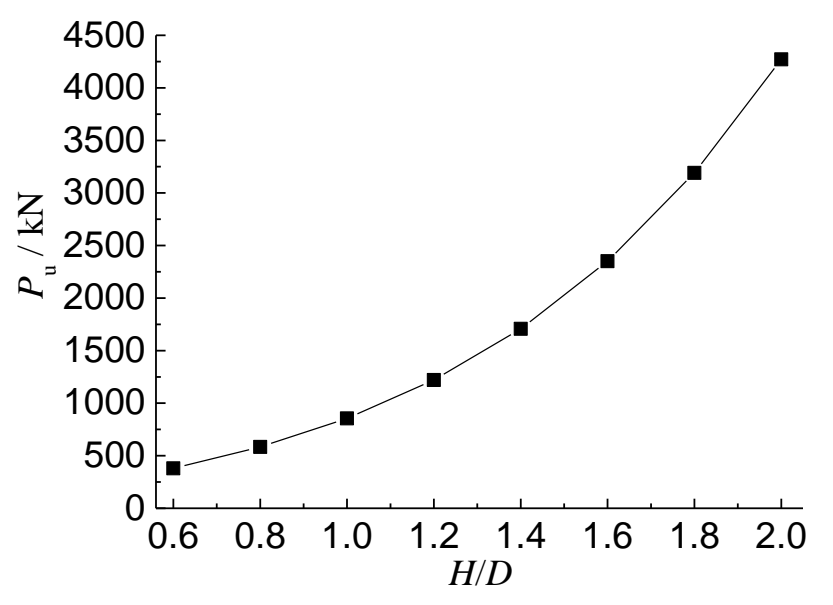

Fig. (9). Influence of the ratio of top diameter and height of foundation $H / D$ on horizontal bearing capacity $P_{\mathrm{u}}$.

bucket foundation decreased $19.1 \%$ when $L_{\mathrm{p}}$ changed from $85.0 \mathrm{~m}$ to $105.0 \mathrm{~m}$. It can be found the horizontal bearing capacity decreased greatly with the value of $L_{\mathrm{p}}$ increased. 
Therefore, the depth of seabed is another important parameter during bucket foundation design. When marine engineering with deep seabed and single bucket foundation could hardly meet the requirements, $2 \sim 4$ bucket foundations combined as integration should be used. It is more difficult and complex to design multiple union bucket foundations.

\section{CONCLUSION}

(1) A new bucket foundation with partial inclined wall has been proposed in this article. Based on limit equilibrium analysis of three-dimensional stress state of foundation, the calculation method of horizontal bearing capacity of the new bucket foundation has been deduced, which has been verified by model tests.

(2) The horizontal bearing capacity of the new bucket foundation increased effectively with dip angle of wall increased. This feature of the new bucket foundation would improve and optimize the design of traditional bucket foundation.

(3) The horizontal bearing capacity of the new bucket foundation linearly increased with the proportional coefficient of horizontal subgrade reaction increased. It is urgently necessary to establish a test method to measure the value of proportional coefficient of horizontal subgrade reaction of seabed, and provide corresponding detail sheets to search the value for users conveniently.

(4) The horizontal bearing capacity of the new bucket foundation increased rapidly with top diameter of bucket foundation or height of bucket foundation increased, while which decreased with the depth of seabed increased.

\section{CONFLICT OF INTEREST}

The authors confirm that this article content has no conflict of interest.

\section{ACKNOWLEDGEMENTS}

This research was funded by National Science Foundation of China (41306088) and Anhui Provincial Natural Science Foundation (1208085QE85, 1308085ME61).

\section{REFERENCES}

[1] M Iskander, and S Ei-Gharbawy, "Performance of suctioncaissons in sand and clay", Can. Geotech., vol. 39, pp. 576-584, 2002.

[2] L Zdravkovic, DM Potts, and RJ Jardine, "Aparametric study of the pull-out capacity of bucketfoundations in soft clay", Geotechnique, vol. 51, pp. 55-67, 2001.

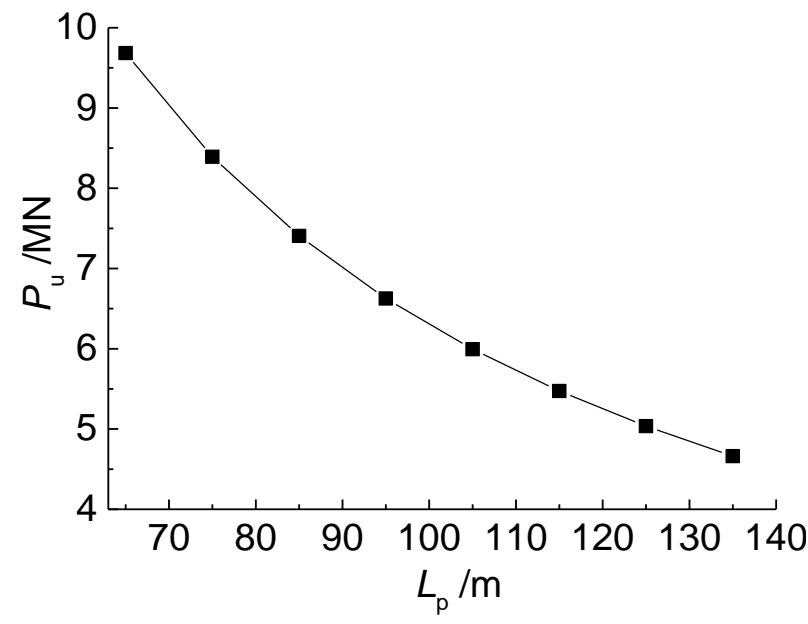

Fig. (10). Influence of the height of acting point $L_{\mathrm{p}}$ on horizontal bearing capacity of foundation $P_{\mathrm{u}}$.

[3] C P Aubeny, S W Han, and JD Murff, "Inclined loadcapacity of suction caissons", Int. J. Num. Analy. Methods Geomech., vol. 27, pp. 1235-1254, 2003.

[4] G T Houlsby, and B W Byrne, "Design procedures for installation of suction caissons in sand", Geotech. Eng., vol. 158, pp. 135-144, 2005.

[5] G-S Wang, L-W Kong, and J-L Yang, "Interaction of soil mass and bucket foundation under horizontal loads", Eng. Mech., vol. 21, pp. 107-113, 2004.

[6] S-C Jin, Y-T Zhang, and Y-H Yang, "Research on horizontal ultimate bearing capacity of suction bucket foundation in saturated sand ground", Rock Soil Mech., vol. 34, Supp.1, pp. 221-227, August 2013.

[7] Tjelta Tor-Inge, and Statoil A/S, "Geotechnical aspects of bucket foundations replacing piles for the Europipe 16/11- E Jacket", OTC 7379, Houston, 1995.

[8] Z-L Yuan, Y-L Qin, and H-Y Tang, "Bucket Foundation Platform in Shallow Sea", Beijing: Petroleum Industry Press, 2010, pp. 1-9.

[9] M Zeinoddini, J Keyvani, M Nabipour, "Tapered suction caissons: A numerical investigation into their pull-out performance", China Ocean Eng., vol. 23, pp. 695-707, April 2009.

[10] W-Q Xu, F-F Yuan, H-B Li, "Horizontal bearing capacity of tapered bucked foundations based on three-dimensional finite element numerical analysis", J. Graduate Uni. Chinese Acad. Sci., vol. 29, pp. 200-205, February 2012.

[11] X-Y Sun, M-T Luan, and X-W Tang, "Study of horizontal bearing capacity of bucket foundation on saturated soft clay ground", Rock Soil Mech., vol. 31, pp. 667-672, February 2010.

[12] X-C Shi, R-Q Xu, and X-N Gong, "Experimental study on horizontal bearing capacity of single bucket foundation", Chin. J. Geotech. Eng., vol. 21, pp. 723-726, June 1999.

[13] Z-W Liu, J-H Wang, and C-R Qin, "Research on the horizontal bearing capacity of bucket foundations", Chin. J. Geotech. Eng., vol. 22, pp. 691-695, June 2000.

(C) Jin-long and Lu-wang; Licensee Bentham Open.

This is an open access article licensed under the terms of the Creative Commons Attribution Non-Commercial License (http://creativecommons.org/licenses/ by-nc/3.0/) which permits unrestricted, non-commercial use, distribution and reproduction in any medium, provided the work is properly cited. 